BLS 32, No 1 2006. DOI: http://dx.doi.org/10.3765/bls.v32i1.3439 (published by the Berkeley Linguistics Society and the Linguistic Society of America)

\title{
Several Problems for Predicate Decompositions
}

\author{
JOHN BEAVERS and ITAMAR FRANCEZ \\ Stanford University
}

\section{Introduction}

This paper examines argument/oblique alternations, where a semantic argument of a predicate may be morphosyntactically realized either as a direct argument (e.g subject or object) or as an oblique. The conative alternation in (1) is an example.

(1) a. Kim cut the pie.

b. Kim cut at the pie.

In (1a) the patient the pie is realized as an object and in (1b) it is realized as an oblique marked by the preposition $a t$. There is a semantic effect associated with this alternation: when the pie is a direct object it is known to have necessarily been affected in some way, but when it is an oblique it may or may not have been affected, depending on the context (i.e. it is underspecified for affectedness). We point out three general properties of such alternations, which a theory of argument realization should ideally capture. These are given in (2)-(4).

(2) Implicational Contrasts: Direct argument variants often entail additional properties of the alternating participant not entailed by oblique variants.

What a direct argument variant says about the alternating participant entails what the oblique variant says about the alternating participant, but not conversely. In the conative alternation in (1) for example, all else being equal, (1a) specifies a result not specified (nor contradicted) for (1b). Following Beavers (2005, 2006, in prep), we argue that this property holds for many other alternations as well.

(3) Root Dependency: The contrast exhibited by a given verb in a given alternation depends on the verb.

While the contrast an alternation exhibits may be characterized very generally, the exact contrast is always verb-dependent.

(4) Verb Hierarchies: For certain alternations, the ability of certain verbs to alternate predicts the ability of other verbs to do so. 
We argue that these properties derive from the lexical semantic properties that verbs associate with their arguments. We claim that predicate decomposition theories of argument realization (Dowty 1979, Levin and Rappaport (Hovav) 1988, 1995, Pinker 1989, Gropen et al. 1991, Wunderlich 1997, Van Valin and LaPolla 1997, Rappaport Hovav and Levin 1998, Davis 2001, inter alia) fail to capture these properties, because they are inherently structural rather than semantic in nature, i.e. they base generalizations on the structure of semantic representations, but these structures are not necessarily tied to any independently motivated semantics (a point made by Koenig and Davis 2004). We argue instead that entailment-based approaches to argument realization (Ladusaw and Dowty 1988, Dowty 1989, 1991, Primus 1999, Ackerman and Moore 2001, Beavers 2005, 2006, in prep) provide an appropriate language for capturing these properties.

\section{Predicate Decomposition vs. Entailment-Based Approaches}

Theories of predicate decomposition posit two components to a verb's meaning: an event template built of a small number of basic predicates (e.g. CAUSE, BECOME) that capture the subevent structure of the event, and an idiosyncratic root associated with the particular verb, as in the following example from Rappaport Hovav and Levin (1998:119, (33)):

(5) Phil swept the floor clean.

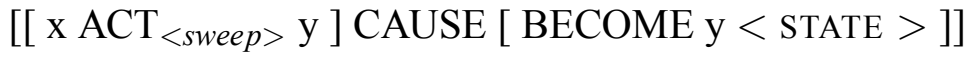

In (5) the template defines an ACT event between two participants $x$ and $y$, subscripted by the idiosyncractic root SWEEP, indicating that the ACT is a sweeping event. This serves as the first argument of a CAUSE predicate whose second argument is a resultant BECOME predicate indicating that $y$ comes to change state as a result of the event. The relative prominence of $x$ and $y$ in the template determines their relative morphosyntactic prominence in the clause, such that the least embedded participant is the subject and the more embedded participant is the object.

In entailment-based approaches a verb instead assigns to each argument a set of entailments describing its role in the event, which determine argument realization according to some set of mapping principles. For example, Dowty (1991) defines subject/object selection in terms of two thematic proto-roles defined as follows (ignoring entailments having to do with existence independent of the event which Dowty posits but suggests may not ultimately be relevant):

(6) Proto-Agent (Dowty 1991:572, (27))

i. volitional involvement in the event or state

ii. $\quad$ sentience (and/or perception)

iii. causing an event or change of state in another participant

iv. movement (relative to the position of another participant)

\footnotetext{
Proto-Patient (Dowty 1991:572, (28))

i. undergoes change of state

ii. incremental theme

iii. causally affected by another participant

iv. stationary relative to movement of another participant
} 
On Dowty's approach the argument bearing the most proto-agent entailments is the subject and the argument bearing the most proto-patient entailments is the object (Dowty 1991:576). In (5) Phil is assigned all of the proto-agent entailments in (6) but none of the proto-patient entailments, while the floor is assigned all of the protopatient entailments but none of the proto-agent entailments. Thus Phil is the subject and the floor is the object. The specific implementations aside, the crucial difference between these theories is that in decompositional approaches the structure of the event template determines argument realization whereas in entailment-based approaches it is the entailments assigned to each participant. In the next several sections we show how decomposition theories do not naturally capture the properties in (2)-(4), while entailment-based approaches provide a natural language for capturing these properties.

\section{Implicational Contrasts}

Consider first the well-known locative alternation (Fillmore 1968):
(7) a. Kim loaded hay onto the wagon.
(locatum $=\mathrm{DO}$, location $=\mathrm{OBL}$ )
b. Kim loaded the wagon with hay.
(location $=\mathrm{DO}$, locatum $=\mathrm{OBL}$ )

In (7) there are two non-causer participants, a locatum (the thing that moves) and a location (where the locatum moves to), and either may be realized as the direct object, in which case the other is realized as an oblique marked by an appropriate preposition. This alternation is associated with a well-known semantic effect: the location receives a "holistic" interpretation (it comes to be completely full) when realized as the direct object (Anderson 1971). This is shown in (8), where the direct object variant is infelicitous with continuations contradicting the holistic reading, while the oblique variant is compatible both with continuations in which holistic affectedness is entailed and those in which it is contradicted:

(8) a. \#Kim loaded the wagon with hay, and had extra room for the grain.

b. Kim loaded hay onto the wagon, and had extra room for the grain.

c. Kim loaded hay onto the wagon, filling it up completely.

Levin and Rappaport (1988) characterize this contrast in terms of what they refer to as the "paraphrase property": the location direct object variant ( $7 b$ ) entails the location oblique variant (7a) but not vice versa. They capture this in terms of two distinct but related event templates (ibid:26, (24)):

(9) a. John loaded hay onto the wagon. [ $x$ cause $[y$ to come to be at $z] / \mathrm{LOAD}]$

b. John loaded the wagon with hay.

[[ $x$ cause $[z$ to come to be in STATE $]]$ BY MEANS OF [ $x$ cause $[y$ to come to be at $z] / \mathrm{LOAD}]]$ (change-of-location, cf. put)

(change-of-state, cf. fill) 
On this analysis (9a) is essentially a change-of-location event of the locatum, whereas $(9 b)$ is a change-of-state event of the location by means of a change-oflocation of the locatum. Levin and Rappaport (1988:25, (21)-(22)) propose a direct object linking rule in which the least embedded participant that is either moved or changed (i.e. the least embedded non-causer) is linked to the direct object. The morphosyntactic and semantic facts follow directly from this approach. Each template makes a different argument more prominent (less embedded) in the decomposition, which determines different direct object linking. Furthermore, (9b) embeds (9a), predicting the paraphrase relationship.

However, this approach is problematic for two reasons. First, both variants entail some degree of affectedness for both participants (at least partly moved or filled) whether holistic or not (as noted by Jackendoff 1990:129-130). However, (9) does not reflect the entailments of at least partial affectedness for either participant, and thus it is also not clear how (9) encodes the holistic vs. at least partial affectedness contrast for the location. Furthermore, it is not clear in general what kind of affectedness is encoded in (9b), which only says that the location comes to be in some state. But why this state is interpreted as a state of being completely full (rather than some other state) is unclear. Gropen et al. (1991:162) describe the holistic effect as "most natural" when the location is more prominent, but there is rarely an explicit explanation for why this is the case or how the interpretation actually arises.

Second, and more importantly, the "paraphrase property" is more complicated than (9) suggests. The entailment relation between the variants in (7) rests crucially on the fact that the locatum is a mass noun. However, bare plural/mass noun objects are known to force atelic readings for all transitive dynamic predicates, locative or otherwise, obscuring any potential holistic reading that might arise (Verkuyl 1972). When the locatum is a definite specific NP, it also yields a holistic reading (a point also made by Fillmore 1977, Jeffries and Willis 1984, Dowty 1991):

(10) a. \#Kim loaded the hay onto the wagon, but needed a truck for the rest.

b. Kim loaded the wagon with the hay, but needed a truck for the rest.

c. Kim loaded the wagon with the hay, leaving none behind.

Thus the paraphrase property, as much as it can be called that, is a general property that holds relative to each participant: each variant associates an additional property with its direct object not associated with the corresponding oblique in the other variant. In fact, as discussed extensively in Beavers (2005, 2006, in prep), this relativized version of the paraphrase property applies to many alternations that involve notions others than holistic affectedness and grammatical functions other than object, as shown in the following examples (cf. Beavers 2005:30-31, (6), (9)):

(11) Reciprocal alternation

a. The car and the truck collided.

b. The car collided with the truck.
(Underspecified motion)

(car and truck in motion)

(car in motion; truck not necessarily) 


\section{(12) Dative alternation}

a. John sent Mary the letter.

b. John sent the letter to Mary.

\section{(Underspecified possession/goal)}

(Mary a goal and possessor)

(Mary not necessarily possessor)

Such data show that the morphosyntactic contrast between direct argument and oblique realization for a single participant corresponds to a very general, participantbased semantic contrast characterizable informally as in (13) (cf. Ackerman and Moore 2001, Beavers 2005, 2006, in prep).

(13) In semantically contentful argument/oblique alternations direct arguments are specified for properties left underspecified for corresponding obliques.

The principle in (13) cross-cuts a range of possible alternations and semantic properties. Decompositions do not capture this since all they encode are structural differences between co-arguments in the decomposition (as discussed extensively in Koenig and Davis 2004), in particular regarding their relative embeddedness. But embeddedness is not itself inherently linked to any particular semantic contrast, least of all the one in (13). Ideally a theory of alternations should link the morphosyntactic contrasts to the appropriate semantic contrasts defined independently.

Entailment-based approaches to argument realization provide a language for doing exactly this. Since the semantics of a verb consists of sets of entailments, which constitute the thematic roles of the verb's arguments, then by definition there can be subset relations between such sets. Subset relations encode exactly the sorts of implicational contrasts discussed above:

(14) For any two sets of entailments $R$ and $Q$ assigned to a participant $x$, if $R \subset Q$ then $Q$ encodes strictly more information about $x$ (contains more entailments) than $R$.

We can therefore place the following general constraint on linking rules governing argument/oblique alternations, restricting the semantic contrasts they allow:

(15) An argument $x$ of verb $V$ has entailments $Q_{V}$ as a direct argument and entailments $R V$ as an oblique, where $R V \subset Q_{V}$.

Linking rules for particular alternations specify which sets of entailments are relevant. For example, however the locative alternation is analyzed, we would expect it to yield the following assignments of entailments, which obeys (15):

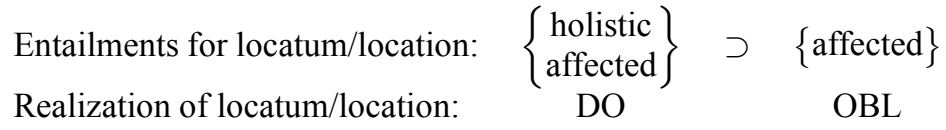

Whichever participant is the direct object receives one additional entailment (the holistic interpretation) not associated with it as an oblique. Thus what were structural asymmetries in decompositions are implicational asymmetries in entailmentbased approaches, capturing the contrast in (13) in an independently motivated way. 


\section{Root Dependency}

The contrast governed by a given alternation varies, sometimes dramatically, depending on the verb that occurs in the alternation. Consider cutting, slicing, and chipping verbs, which exhibit realization patterns similar to locative alternations:
a. Kim cut/sliced/chipped the window with the diamond.
(w. affected)
b. Kim cut/sliced/chipped the diamond on the window.
(d. affected)

We again have a three participant situation: some agent (Kim) moves some locatum/instrument (the diamond) into mutual contact with some location (the window), and one participant becomes affected as a result (see Gawron 1986 on such events with hit and Guerssel et al. 1985, Laughren 1988 on such an analysis for conative alternations with these verbs). In (17a) the location is the object and is entailed to have been affected, while in (17b) the locatum is the object and comes to be affected. In both cases the oblique is underspecified for any effect. Thus we have something like the locative alternation: either non-causer may be direct object, in which case it is specified for an effect for which it is not specified as an oblique. Though not canonical locative alternations, (17) share many properties in common with spray/load alternations that suggest these two are different manifestations of the same alternation (Fillmore 1977, Dowty 1991, Beavers 2005, 2006). First, both cases involve inherently three argument verbs with the same morphosyntax for the oblique participants (with-marking for the locatum, in(to)/on(to) marking for the location). Second, the locatum is always intermediate in the force-dynamic chain corresponding to both kinds of events (following the terminology of Croft 1991), i.e. the agent first acts on the locatum and then on the location:

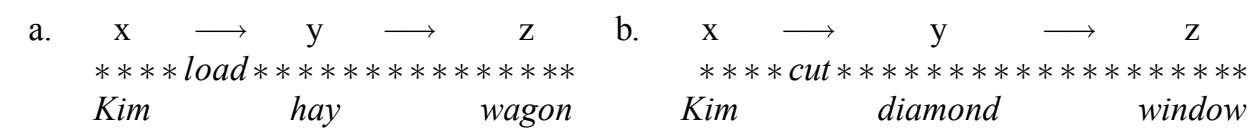

Finally, the locatum in both kinds of events always moves relative to the location.

Thus we have two verb classes, the spray/load and cut/slice classes, which describe similar events and exhibit the same argument realization alternation. Yet the contrast depends on the verb class: it is the (under)specification of holistic affectedness for spray/load and the (under)specification of affectedness for cut/slice. To be sure, the conative also allows both types of contrasts:
a. Kim ate the pie. (holistic) $\Leftrightarrow \quad$ b. Kim ate at the pie. (affected)
c. Kim cut the pie. (affected) $\Leftrightarrow$ d. Kim cut at the pie.

This suggests that the semantics of a given alternation is inherently tied to the verb. In decompositional theories we would expect to treat each verb the same in terms of the geometry of its event templates, e.g. we would expect the with-variants of spray and cut to have the following forms following Levin and Rappaport's (1988) analysis of the locative alternation above (see Guerssel et al. 1985, Laughren 1988 for related decompositions of $c u t$ in conative alternations): 


\section{Several Problems for Predicate Decompositions}

(20) a. load with: [ $[x$ cause $[z$ to come to be in STATE $]]$ BY MEANS OF $[x$ cause $[y$ to come to be at $z] / \mathrm{LOAD}]]$

b. cut with: $[[x$ cause $[z$ to come to be in STATE $]]$ BY MEANS OF [ $x$ cause $[y$ to come to be at $z] / C U T]]$

But such an analysis would not capture the lexical idiosyncrasy, i.e. the fact that the "same" alternation has different semantics with different verbal roots. Presumably, this comes from the root portion of the decomposition (the only thing differentiating the two representations). However, the link between the root and the event template is rarely explicated in detail in such theories (though see Rappaport Hovav and Levin 1998), and in general the root plays no role in assigning particular semantics to any participant, least of all assigning different semantics to a participant depending on its position in the template.

On an entailment-based approach root dependency follows naturally. Different verbs associate different entailments with their arguments; linking rules determine subset relations dependent on the entailments handed to them by the verb. For example, following Beavers (2005, 2006, in prep), assuming that holistic affectedness entails affectedness, whatever linking rule generates the locative paradigm can be seen as stripping away the strongest entailment of affectedness. Spray and cut assign different strongest entailments, generating the contrasts in (21).

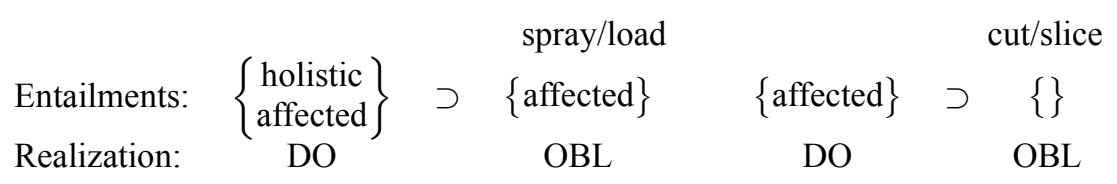

Thus the root is what determines the contrast exhibited by a given alternation. In fact, the very notions of "root" and "template" are no longer ontologically distinct on such an approach. Whereas before the template determined the existence of an alternation in terms of structural asymmetries between co-arguments, this work is here done by subset structures between sets of entailments, which are emergent from the entailments that constitute the semantics associated with a given root.

\section{Verb Hierarchies}

We turn now to the relationships between different verbs regarding their ability to undergo certain alternations. Consider the dative alternation, in which the recipient argument of a three-argument dative verb may be realized as either a first object (FO) of a double-object construction (or as a dative in languages with such a case) or as an allative oblique, marked in English by the preposition to:

(22) a. Kim gave/sent/threw Sandy a ball.

b. Kim gave/sent/threw a ball to Sandy.

Croft et al. (2001) show that, crosslinguistically, verbs meaning give and verbs meaning send form an implicational hierarchy regarding their ability to undergo 
this alternation. Give is less likely than send to show oblique realization, but if give alternates then so does send. It is commonly assumed that FO realization encodes caused possession while oblique realizations encode directed motion (Green 1974, inter alia). Decomposition analyses associate these two meanings with two distinct event templates as in (23), adopted from Rappaport Hovav and Levin (2005) (RH\&L).
a. [ $x$ CAUSE [ y HAVE z ] ]
(causation-of-possession; recipient is FO)
b. [ $\mathrm{x}$ CAUSE [ z GO TO y ] ]
(change-of-location; recipient is oblique)

Since prominence in the template determines morphosyntactic prominence, (23a) yields the FO/dative realization of the recipient and (23b) yields the allative realization. Such analyses generally assume that all ditransitives have both meanings available and thus predict the alternation (see e.g. Pinker 1989). But this does not account for Croft et al.'s generalizations that give does not always alternate and that there is a predictive relationship between give alternating and send alternating. RH\&L argue instead that give-verbs unambiguously encode caused possession, while send-verbs are polysemous. The monosemy of give is evidenced e.g. in the fact that its recipient argument must be interpretable as a possessor in both the FO and the oblique realization for the sentence to be felicitous (Green 1974), unlike send, for which this only holds of the FO variant:
a.\#John sent/gave London a letter.
(must be "London office")

b. John sent/\#gave a letter to London. (must be "London office" for give)

The monosemy of give and the polysemy of send explains why in many languages give-verbs do not alternate while send-verbs do (cf. German, Hebrew; see Francez to appear). However, this does not explain why give alternates in English. RH\&L argue that give alternates in English for information structural and heaviness reasons (among other things; see Wasow 2002), not because of a semantic ambiguity.

This analysis, however, leaves several issues open which are problematic for decomposition approaches. First, why is the allative the relevant oblique marker for give when it alternates? If the alternation with give is unrelated to the directed motion template in (23b), there is no reason to expect the oblique frame give shows up in when it alternates to be the allative one. Yet in all languages we are aware of in which give allows an oblique recipient the marker is the allative. Moreover, in Finnish, which lacks a dative case and a double object construction, the allative is the only way to realize a recipient (Karlsson 1999). RH\&L (2005:11) note that "[r] ecipients can be expressed either as a first object or as the object of the preposition to, since they are semantically compatible with both realizations," suggesting a common semantics to allative and FO realization that predicts the correct alternation for give. However, no semantic commonality is encoded anywhere in (23), and thus such representations miss an important generalization. 
An entailment-based approach captures these generalizations fairly naturally in terms of shared entailments. We posit the following sets of entailments constituting the roles POSSESSOR and GOAL, which again fall in a subset relation as in (13):

$$
\left\{\begin{array}{c}
\mathrm{g} \text { is the endpoint of a path } \\
\mathrm{g} \text { comes to possess a theme } \mathrm{x}
\end{array}\right\} \supset \quad\{\mathrm{g} \text { is the endpoint of a path }\}
$$

Both roles share the entailment of denoting the endpoint of some abstract motion of the theme towards the recipient, where a POSSESSOR additionally comes to possess the theme at the end of the event, i.e. POSSESSORS are affected GOALS (as discussed in Jackendoff 1990:267). This notion of path is necessarily abstract (à la Krifka 1998, Beavers to appear): it refers to a scale of the theme coming to be at or with the goal, i.e. a relation of "central coincidence" following Hale and Keyser (2002:208), a necessary precondition on coming to be possessed. The alternation can be captured in terms of the thematic roles give and send assign to their non-theme arguments and the participants that FO and allative realize, as outlined in (26), while maintaining RH\&L's analysis of give as monosemous.

$$
\begin{aligned}
& \text { Verbs } \\
& \text { give : POSSESSOR } \\
& \text { send : GOAL }
\end{aligned}
$$$$
\begin{aligned}
& \text { Realization Options } \\
& \text { FO : POSSESSOR } \\
& \text { to } \quad: \text { GOAL }
\end{aligned}
$$

The alternation follows straightforwardly. The role assigned by send is compatible with that realized by to, predicting allative realizations with send. FO realization is possible as well since it is not incompatible with the role assigned by send, but FO realization monotonically adds the entailment of possession (since what FO realizes is a superset of what send selects for). Likewise, the role assigned by give is compatible with FO realization, predicting that give shows this realization option. Crucially, since the role assigned by give subsumes that of to, allative realization is trivially also possible for give. But since give inherently determines a stronger semantics the resultant alternation is semantically vacuous (as in (24)). Thus, from the shared entailments in the semantics of the verbs and the realization options we predict that the relevant oblique marker for give is the allative, as it is for other dative verbs, something the templates in (23) do not capture.

A second, related issue is the motivation for the alternation with give. Assuming that give is monosemous, and given that monosemous verbs can nevertheless alternate for reasons of information structure and heaviness, why does give not alternate in all languages with an allative marker? Predicate decompositions provide no way of addressing this question. The entailments we posit determine a unique interaction which explains this. Give is compatible with oblique realization but always determines a stronger meaning, which interacts with the semantics of FO and to to yield a blocking effect: the stronger realization is preferred for expressing the stronger meaning. The allative realization is hence expected to be heavily dispreferred (a preference that may be grammaticalized in some languages). However, 
John Beavers and Itamar Francez

blocking can be overridden if there is some independent need for the alternation. Due to the relative rigidity of English word order, alternations are commonly exploited for various information structural, grammatical, and processing purposes (Givón 1984). Thus, despite its semantic vacuity, the alternation with give is motivated functionally in English, overriding the blocking effect. Our explanation of Croft et al.'s generalization is therefore that oblique variants with both give and send are always possible, but vacuous alternations as with give are only exploited in a language in which they are functionally motivated. This predicts the lower frequency of alternations with give, and the implicational relationship to send.

\section{Conclusions}

We discussed three properties of argument/oblique alternations, implicational contrasts, root dependency, and verb hierarchies, which a theory of argument realization should capture. We argued that entailment-based approaches provide a language for capturing such generalizations, whereas decomposition based approaches do not, due to their structural nature. In principal, decompositional approaches can be made to capture at least some of these properties, e.g. by augmenting the structures with semantic information that determines argument realization (as in Jackendoff 1990) or else relating decompositions via meaning postulates in a way that predicts the participant-based contrasts discussed above. Yet such augmentations would themselves constitute a semantic structure upon which linking constraints could be stated, obviating the need for the decompositions themselves. Whether this is a desired research program is a matter for future work, but the questions raised here pose challenges for such theories.

\section{Acknowledgments}

We would like to thank Mark Gawron, Beth Levin, Tanya Nikitina, and Malka Rappaport Hovav for their discussion and comments.

\section{References}

Ackerman, Farrell and John Moore. 2001. Proto-Properties and Grammatical Encoding: A Correspondence Theory of Argument Selection. Stanford, CA: CSLI Publications.

Anderson, Stephen R. 1971. On the Role of Deep Structure in Semantic Interpretation. Foundations of Language 7(3):387-396.

Beavers, John. 2005. A Semantic Analysis of Argument/Oblique Alternations in HPSG. In S. Müller, ed., Proceedings of the 2005 HPSG Conference, 28-48. Stanford, CA: CSLI Publications.

Beavers, John. 2006. Thematic Role Specificity and Argument/Oblique Alternations in English. In Proceedings of WECOL 2004. University of Southern California, Los Angeles. 
Beavers, John. In prep. Argument/Oblique Alternations and the Structure of Lexical Meaning. Ph.D. diss., Stanford University.

Beavers, John. To appear. Scalar Complexity and the Structure of Events. In J. Dölling and T. Heyde-Zybatow, eds., Event Structures in Linguistic Form and Interpretation. Berlin: Mouton de Gruyter.

Croft, William. 1991. Syntactic Categories and Grammatical Relations: The Cognitive Organization of Information. Chicago: University of Chicago Press.

Croft, William, Jóhanna Barð̋dal, William Hollmann, Maike Nielsen, Violeta Sotirova, and Chiaki Taoka. 2001. Discriminating Verb Meanings: The Case of Transfer Verbs. Handout, LAGB Autumn Meeting, Reading.

Davis, Anthony. 2001. Linking by Types in the Hierarchical Lexicon. Stanford, CA: CSLI Publications.

Dowty, David. 1979. Word Meaning and Montague Grammar. Dordrecht: Reidel.

Dowty, David. 1989. On the Semantic Content of the Notion 'Thematic Role'. In G. Chierchia, B. H. Partee, and R. Turner, eds., Properties, Types, and Meaning, 69-129. Dordrecht: Kluwer Academic Publishers.

Dowty, David. 1991. Thematic Proto-roles and Argument Selection. Language 67(3):547-619.

Fillmore, Charles J. 1968. The Case for Case. In E. Bach and R. T. Harms, eds., Universals in Linguistic Theory, 1-90. New York: Holt.

Fillmore, Charles J. 1977. The Case for Case Reopened. In P. Cole and J. M. Sadock, eds., Grammatical Relations, 59-82. New York: Academic Press.

Francez, Itamar. To appear. Possessors, Goals and the Classification of Ditransitive Predicates: Evidence from Hebrew. In Empirical Issues in Syntax and Semantics 6.

Gawron, Jean Mark. 1986. Situations and Prepositions. Linguistics and Philosophy 9:327-382.

Givón, Talmy. 1984. Direct Object and Dative Shifting: Semantic and Pragmatic Case. In F. Plank, ed., Objects: Towards a Theory of Grammatical Relations, 151-182. London: Academic Press.

Green, Georgia. 1974. Semantic and Syntactic Regularity. Bloomington, IN: Indiana University Press.

Gropen, Jess, Steven Pinker, Michelle Hollander, and Richard Goldberg. 1991. Affectedness and Direct Objects: The Role of Lexical Semantics in the Acquisition of Verb Argument Structure. Cognition 41:153-195.

Guerssel, Mohamed, Kenneth Hale, Mary Laughren, Beth Levin, and Josie White Eagle. 1985. A Cross-linguistic Study of Transitivity Alternations. In W. H. Eilfort, P. D. Kroeber, and K. L. Peterson, eds., CLS 21, Part 2: Papers from the Parasession on Causatives and Agentivity, 48-63. Chicago Linguistic Society.

Hale, Kenneth L. and Samuel Jay Keyser. 2002. Prolegomenon to a Theory of Argument Structure. Cambridge, MA: MIT Press.

Jackendoff, Ray. 1990. Semantic Structures. Cambridge, MA: MIT Press.

Jeffries, Lesley and Penny Willis. 1984. A Return to the Spray Paint Issue. Journal 
of Pragmatics 8:715-729.

Karlsson, Fred. 1999. Finnish: An Essential Grammar. New York: Routledge.

Koenig, Jean-Pierre and Anthony Davis. 2004. The KEY To Lexical Semantic Representations. Ms., University at Buffalo, the State University of New York.

Krifka, Manfred. 1998. The Origins of Telicity. In S. Rothstein, ed., Events and Grammar, 197-235. Dordrecht: Kluwer Academic Publishers.

Ladusaw, William and David R. Dowty. 1988. Toward a Non-grammatical Account of Thematic Roles. In W. Wilkins, ed., Thematic Relations, 62-72. San Diego, CA: Academic Press.

Laughren, Mary. 1988. Toward a Lexical Representation of Warlpiri Verbs. In W. Wilkins, ed., Thematic Relations, 215-242. San Diego, CA: Academic Press.

Levin, Beth and Malka Rappaport. 1988. What to do with $\theta$-Roles. In W. Wilkins, ed., Thematic Relations, 7-36. San Diego, CA: Academic Press.

Levin, Beth and Malka Rappaport Hovav. 1995. Unaccusativity: At the SyntaxLexical Semantics Interface. Cambridge, MA: MIT Press.

Pinker, Stephen. 1989. Learnability and Cognition. Cambridge, MA: MIT Press.

Primus, Beatrice. 1999. Case and Thematic Roles: Ergative, Accusative and Active. Tübingen: Max Niewmeyer Verlag.

Rappaport Hovav, Malka and Beth Levin. 1998. Building Verb Meanings. In M. Butt and W. Geuder, eds., The Projection of Arguments: Lexical and Compositional Factors, 97-133. Stanford, CA: CSLI Publications.

Rappaport Hovav, Malka and Beth Levin. 2005. All Dative Verbs are Not Created Equal. Ms., Hebrew University of Jerusalem.

Van Valin, Robert D. and Randy J. LaPolla. 1997. Syntax: Structure, Meaning, and Function. Cambridge, UK: Cambridge University Press.

Verkuyl, Henk J. 1972. On the Compositional Nature of the Aspects. Dordrecht: Reidel.

Wasow, Thomas. 2002. Postverbal Behavior. Stanford, CA: CSLI Publications.

Wunderlich, Dieter. 1997. Cause and the Structure of Verbs. Linguistic Inquiry 28(1):27-68.

John Beavers

Itamar Francez

Stanford University

Department of Linguistics

Margaret Jacks Hall

Stanford, CA 94305-2150

jbeavers@csli.stanford.edu

ifrancez@stanford.edu 